\title{
Safety of nurse-led intravitreal injection of dexamethasone (Ozurdex) implant service. Audit of first 1000 cases
}

\author{
Vasant Raman ${ }^{1} \cdot$ Alison Triggol ${ }^{1} \cdot$ Tomas Cudrnak $^{1} \cdot$ Papadedes Konstantinos $^{1}$ \\ Received: 8 April 2020 / Revised: 7 July 2020 / Accepted: 16 July 2020 / Published online: 29 July 2020 \\ (c) The Author(s), under exclusive licence to The Royal College of Ophthalmologists 2020
}

\begin{abstract}
Purpose To assess the safety of nurse-led services of intravitreal injection of dexamethasone implant.

Methods An audit of intravitreal injection of dexamethasone implant service in our unit revealed a significant delay in the delivery of injection from the time a clinical decision was made. The limiting factors were an inadequate number of injectors and limited capacity. The constraint in capacity was addressed by moving the service from the theatre to the cleanroom in the outpatients setting. Two senior nurse practitioners in the existing pool of injectors, experienced in intravitreal anti-VEGF injection, were trained to deliver the intravitreal dexamethasone implant service. A safety audit was carried out after they had completed 1000 cases.

Results The nurse practitioners administered 1006 injections from February 2017 to October 2019. There was no case of endophthalmitis $(0 \%)$ or other visually significant complications like retinal detachment, vitreous haemorrhage, hypotony or iatrogenic cataract. One patient had incomplete scleral penetration of the implant, but this resolved without any sequelae. The waiting time to inject the implant nearly halved from 29.5 to 15 days in the nurse-led service. A patient satisfaction survey was overwhelmingly positive, with the majority advocating for the continuation of the nurse-led service.

Conclusion The current cohort of experienced nurses providing anti-VEGF injections can be trained under supervision to inject the intravitreal dexamethasone implant (Ozurdex). This is safe, additionally effective in streamlining the service and reducing the waiting time for delivery of the steroid implant.
\end{abstract}

\section{Introduction}

The safety profile of nurse practitioners delivering an intravitreal anti-VEGF injection service has been well established $[1,2]$. In most eye units across the UK, nurses are exclusively providing the intravitreal anti-VEGF injection services [3], whereas others adopt a mixed model consisting of nurses and doctors. Allied healthcare professionals and nurse practitioners doing invasive procedures are not novel, and neither recent in medical practice [4]. In fact, nurse practitioners and physician's assistants were performing invasive procedures in other specialities almost two decades [5] before the first publication [1] on intravitreal anti-VEGF drug delivery by

Vasant Raman

vasant.raman@nhs.net

1 Royal Eye Infirmary, University hospitals of Plymouth NHS Trust, Derriford, Plymouth PL6 8DH, UK nurse practitioners. With a shortage of doctors [6] and an ageing population, the need to find creative means of delivering the intravitreal pharmacotherapy has become dire. The service demand for intravitreal injection has further increased with the introduction of steroid implants (dexamethasone \& fluocinolone acetonide) for treating macular oedema secondary to diabetic maculopathy, retinal venous occlusion and non-infectious uveitis. The number of intravitreal injections has increased enormously over the years in our unit, like elsewhere in the country. Although this has stabilised to some extent for anti-VEGF injections, there has been a surge in demand for dexamethasone implant (Table 1).

\section{Material and methods}

An audit of the dexamethasone implant service in our unit in 2016 showed an inordinate delay of more than 4 weeks wait (Table 2) after the clinical decision was made to inject. 


\section{Resource constraint}

The limiting factors identified were a lack of capacity in terms of the number of sessions (15 injections per session) and the need for additional injectors.

\section{Restructured and streamlined service in the cleanroom}

To reduce the waiting time and to streamline the service, the injection of dexamethasone implant was moved from the theatre to the cleanroom in the outpatient's setting alongside the anti-VEGF service. It was opined that the capacity in a doctor driven service in the theatre would never match the ever-increasing demand for intravitreal pharmacotherapy. Hence a nurse-driven service in the outpatients setting would be the only long-term solution to the stability of the service. Since 2018, all the intravitreal dexamethasone implants are being delivered in the cleanroom by nurses (Fig. 1). When this service was set up, care was taken to keep the anti-VEGF and dexamethasone implant services as a distinct entity to prevent a preferential waiting time of one over the other. Expansion of the capacity was achieved by increasing the number of injection sessions in a week. Two senior nurses who were experienced in delivering antiVEGF injections were trained to inject the dexamethasone implant.

\section{Nurse training and reaccreditation}

All the nurses involved in performing intravitreal injection in our unit are trained and accredited by the medical and vitreo-retina consultant, with a reaccreditation every 2 years. The senior-most nurse who had undertaken more than

Table 1 Total number of anti-VEGF and Ozurdex injections per annum in our unit.

\begin{tabular}{llll}
\hline Year & $\begin{array}{l}\text { No of anti-VEGF } \\
\text { injection/year }\end{array}$ & $\begin{array}{l}\text { No of dexamethasone } \\
\text { implants/year }\end{array}$ & $\begin{array}{l}\text { Ratio between } \\
\text { anti-VEGF/ } \\
\text { Ozurdex }\end{array}$ \\
\hline 2016 & 7151 & 298 & $24: 1$ \\
2017 & 6990 & 487 & $14: 1$ \\
2018 & 7719 & 502 & $15: 1$ \\
\hline
\end{tabular}

10,000 intravitreal injections was trained to provide the intravitreal Ozurdex injection service. The initial training was carried out in pigs' eye, followed by injection on 20 patients supervised by a consultant. A second nurse was trained 3 months later to join the service. A safety audit was undertaken after the completion of 1000 cases by the 2 nurses.

This was a retrospective audit of the first 1000 intravitreal injection of dexamethasone implant (Ozurdex) delivered by nurse practitioners in a designated cleanroom meant for providing intravitreal injections. The audit department of the University hospitals of Plymouth approved this project (CA_2019-20-155). The data for the audit on intravitreal dexamethasone implant were extracted from the EPR (Medisoft).

\section{Procedure for injecting Ozurdex by nurse injectors}

Local anaesthetic proxymetacaine $0.5 \%$ administered $\times 3$.

Antiseptic preparation of the periocular skin and conjunctiva carried out with diluted $10 \%$ Povidone iodine. Eye to be injected draped, and speculum inserted. Injection site measured $4 \mathrm{~mm}$ from the limbus in all patients irrespective of their lens status. Intravitreal Ozurdex implant primed.

Conjunctiva displaced slightly and a small intrascleral tunnel made with the tip of the needle and the implant injected. Following removal of the injector, the site is plugged for $30 \mathrm{~s}$ with cotton tipped applicator dipped in Povidone iodine. Stat dose of guttae chloramphenicol $0.5 \%$

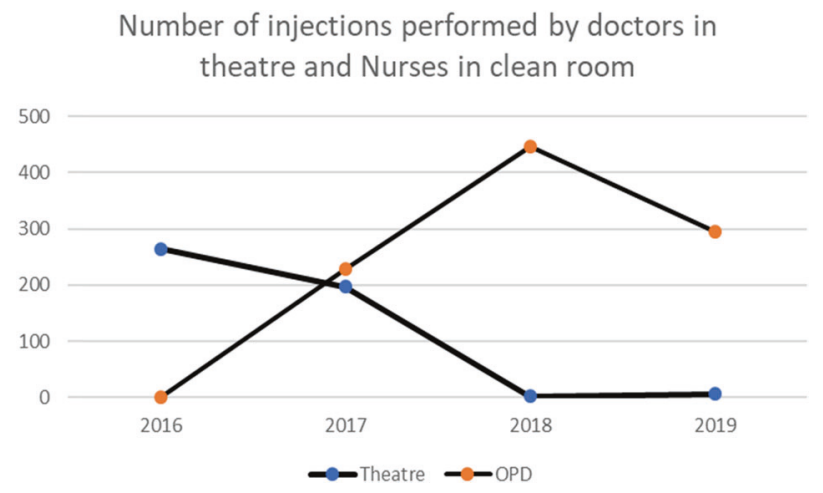

Fig. 1 Graph showing the trend for intravitreal dexamethasone implant injection by Nurses in clean room Vs Doctors in theatre between 2016 to 2019. The service is fully driven by nurses since 2018.
Table 2 Total number of Ozurdex injections performed by nurses during the study period (February 2017 to October 2019).

\begin{tabular}{lllll}
\hline Year & $\begin{array}{l}\text { Theatre only injections } \\
\text { (by doctors) }\end{array}$ & $\begin{array}{l}\text { Average days on W/L in } \\
\text { theatre (only injections) }\end{array}$ & $\begin{array}{l}\text { Cleanroom injection } \\
(\text { OPD) by nurses }\end{array}$ & $\begin{array}{l}\text { Average days on } \\
\text { W/L OPD }\end{array}$ \\
\hline 2016 & 265 & 29 & $\times$ & $\times$ \\
2017 & 197 & 30 & 224 & 16 \\
2018 & $\times$ & $\times$ & 397 & 14 \\
2019 & $\times$ & $\times$ & 385 & 15 \\
\hline
\end{tabular}


Table 3 Results of the patient satisfaction questionnaire for intravitreal ozurdex injection by nurses in the clean room.

1. Please rate your experience of the Ozurdex injection today $(0$ - very

bad to 5-excellent, please feel free to add any comments)

2. Please rate your experience on previous occasions in our theatre (REI Day case unit on the 7th floor) - if applicable (0-very bad to 5 - excellent, please feel free to add any comments)
32 patients responded.

$31 / 32$ rated 5 (excellent) on the scale- $-96 \%$

$1 / 32$ rated $4-4 \%$

24 patients responded.

$14 / 24$ rated 5 (excellent $)=58 \%$

$5 / 24$ rated it as $4=20 \%$

$5 / 24$ rated it as $3=20 \%$

\begin{tabular}{|c|c|c|c|c|c|}
\hline & Strongly agree & Agree & Uncertain & Disagree & Strongly disagree \\
\hline $\begin{array}{l}\text { 1. The nurse made sure I was comfortable and pain free during my } \\
\text { injection }\end{array}$ & $31 / 32=96 \%$ & $1 / 10=4 \%$ & & & \\
\hline 2. Nursing staff appear knowledgeable and competent & $29 / 32=90 \%$ & $3 / 32=10 \%$ & & & \\
\hline 3. I would be happier with a doctor giving my eye injection & & $12 / 32=37.5 \%$ & & & $20 / 32=62.5 \%$ \\
\hline 4. I am dissatisfied with some things about the care I received & & & & $3 / 32=10 \%$ & $29 / 32=90 \%$ \\
\hline
\end{tabular}

applied. Patient asked to count fingers and nurse injectors are advised to seek immediate medical help if there is no vision or severe pain.

\section{Results}

In the period between February 2017 and October 2019, 1006, injections of dexamethasone implant (Ozurdex) were administered by the nurses. Sixty-six patients injected had prior pars plana vitrectomy. The waiting time for patients receiving the intravitreal steroid implant from the day of listing was considerably lower. This was 15 days for nurseled service in the cleanroom compared to 29.5 days (Table 2) for the procedure performed by doctors in theatre.

\section{Patient questionnaire}

A validated patient satisfaction questionnaire [7] was undertaken 2 months after the service was started. The questionnaire was administered immediately after the patients had the intravitreal steroid implant. They were asked to rate the current service and compare that with the previous episode in the theatre (Table 3). The results of the questionnaire were overwhelmingly positive, with the majority of patients reporting satisfaction with the nurse-led service. Patients appreciated the shorter waiting time and were eager that the nurse-led service continues.

\section{Complications}

There was no case of endophthalmitis $(0 \%)$ or any other sight-threatening complications like vitreous haemorrhage, retinal detachment or iatrogenic cataract. There were no returns to the urgent care department within $48 \mathrm{~h}$ with corneal abrasion or persistent red eye. Previous studies have raised concerns of hypotony in vitrectomised eyes [8]. We did not encounter any case of hypotony and its sequelae like choroidal effusion/haemorrhage. There was one case of incomplete penetration [9] of the implant, but that resolved on conservative management without any adverse effect.

\section{Discussion}

NICE first approved (TA229) (https://www.nice.org.uk/ Guidance/TA229/Resources) the use of intravitreal dexamethasone implant (Ozurdex, Allergan Pharmaceuticals Ireland, Westport Ireland) for treating macular oedema secondary to retinal venous occlusion in July 2011. The indications for Ozurdex further expanded for use in diabetic macular oedema (TA349) (https://www.nice.org. uk/Guidance/TA349/Resources) in July 2015 and for noninfectious uveitis (TA460) (https://www.nice.org.uk/ Guidance/TA460/Resources) in 2017. The service implication for delivering an intravitreal injection of anti-VEGF agents is well known.

Nurse-driven anti-VEGF services have become the norm in various eye units across the UK while the delivery of the steroid implants remains the preserve of doctors.

The Royal College of Ophthalmologist guidelines on intravitreal injection (https://www.rcophth.ac.uk/wpcontent/uploads/2018/02/Intravitreal-Injection-Therapy-

August-2018-2.pdf) fully support the delivery of intravitreal injection by allied healthcare professionals within the trust governance framework. No distinction is made between anti-VEGF injection and the steroid implant. Yet this has 
not been adopted in routine clinical care. The reason for this is equivocal. One plausible reason could be the injection delivery system. Whereas the anti-VEGF agent is injected through a 30 -gauge needle mounted on a $1 \mathrm{ml}$ syringe, the steroid implant is delivered by a 22 -gauge needle attached on a large applicator. The apprehension of letting the nurse practitioners take on this role probably stems from this fact. This is unfounded as invasive procedures like paracentesis abdominis, bone marrow biopsy, GI endoscopy, invasive radiological and urological procedures undertaken in other medical specialities by allied healthcare professionals use much larger bore needles and instruments [10-13]. Also, comparative studies looking at patient satisfaction and clinical outcomes between clinicians and allied healthcare professionals performing invasive procedures in various medical specialities have been similar [14, 15]. The traditional role of nurses has undergone significant changes over the last couple of decades, and more so in ophthalmology. Very few eye units have a dedicated ophthalmic ward, as almost all surgical procedures are undertaken as day cases. Given this, more and more nurses are taking up administrative and managerial roles at the cost of clinical care. We need to tap the enormous potential nurses can offer in assisting clinical care of patients. Their skills should be put to use by training and retaining them for a clinical role. Nurses who volunteer to take up the part of delivering intravitreal injections generally tend to have good dexterity and hand-eye coordination. Training them does not involve considerable expenditure, and once trained, they offer cost savings [16] and efficiency.

The senior-most nurse providing the anti-VEGF injection service in our unit was trained to undertake the injection of the intravitreal dexamethasone implant. This led to a significant fall in the waiting time for patients from 29.5 to 15 days. Patient satisfaction questionnaires conducted a few months after introducing this service were overwhelming. In total, $96 \%$ of patients rated as excellent the service provided by nurses compared to $58 \%$, by doctors in a theatre setting (Table 3). Patients were also happy with the comfort experienced during the procedure, as well as the expertise of the nurses. Many of them commented on the shorter waiting time to receive the implant and felt the whole process in the cleanroom setup in the outpatient's department as being less stressful. Although there may be an element of recall bias with their previous experience in theatre, the emphatic satisfaction expressed with the nurse-driven service favours the continuation of the service. More members of the nursing staff are being trained to increase the pool of injectors to prevent the service from faltering due to non-technical reasons like sickness, leave, resignation, etc. Nurses are also being trained to inject the intravitreal fluocinolone (Iluvein) implant. We anticipate, by the second quarter of this year, nurse injectors will undertake all the intravitreal injections (anti-VEGF, dexamethasone \& fluocinolone implant) except where the intravitreal steroid injection is combined with cataract or vitreoretinal surgery.

\section{Summary}

\section{What was known before}

- Nurses and allied healthcare practitioners can safely provide Intravitreal anti-VEGF injection.

\section{What this study adds}

- This is the first study that looked into nurses injecting intravitreal dexamethasone (Ozurdex) implant.

- This study shows that experienced nurse injectors suitably trained can safely inject intravitreal dexamethasone implant.

\section{Compliance with ethical standards}

Conflict of interest The authors declare that they have no conflict of interest.

Publisher's note Springer Nature remains neutral with regard to jurisdictional claims in published maps and institutional affiliations.

\section{References}

1. Simcock P, Kingett B, Mann N, Reddy V, Park J. A safety audit of the first 10,000 intravitreal ranibizumab injections performed by nurse practitioners. Eye. 2014;28:1161-4. https://doi.org/10. 1038/eye.2014.153

2. Bolme S, Morken TS, Follestad T, Sørensen TL, Austeng D. Task shifting of intraocular injections from physicians to nurses: a randomized single-masked noninferiority study. Acta Ophthalmol. 2020;98:139-44.

3. DaCosta J, Hamilton R, Nago J, Mapani A, Kennedy E, Luckett $\mathrm{T}$, et al. Implementation of a nurse-delivered intravitreal injection service. Eye. 2014;28:734-40.

4. DiSario JA1, Sanowski RA. Sigmoidoscopy training for nurses and resident physicians. Gastrointest Endosc. 1993;39:29-32.

5. William Forrest Maule. Screening for colorectal cancer by nurse endoscopists. N Engl J Med. 1994;330:183-7. https://doi.org/10. 1056/NEJM199401203300307

6. Resnikoff S, Felch W, Gauthier TM, Spivey B. The number of ophthalmologists in practice and training worldwide: a growing gap despite more than 200,000 practitioners. Br J Ophthalmol. 2012;96:783-7.

7. Marshall GN, Hays RD. The patient satisfaction questionnaire short form (PSQ-18). (Publication No. P-7865-RC). Santa Monica, CA: RAND; 1994. 
8. Furino C, Recchimurzo N, Boscia F, Alessio G. Cauterization of Ozurdex wound for the prevention of scleral leakage in vitrectomised eyes. Eur J Ophthalmol. 2018;28:341-3. https://doi.org/10. 5301/ejo.5001059

9. Sherman T, Raman V. Incomplete scleral penetration of dexamethasone (Ozurdex) intravitreal implant. BMJ Case Rep. 2018;11:e227055.

10. Duszak R, Walls DG, Wang JM, Hemingway J, Hughes DR, Small WC, et al. Expanding roles of nurse practitioners and physician assistants as providers of nonvascular invasive radiology procedures. J Am Coll Radiol. 2015; $12: 284-9$.

11. Jackson K, Guinigundo A, Waterhouse D. Bone marrow aspiration and biopsy: a guideline for procedural training and competency assessment. J Adv Pract Oncol. 2012;3:260-5.

12. Maamouri N, Raoof ND, Pastores SM, Voigt LP, Chawla S, Alicea $M$, et al. Safety and feasibility of training nurse practitioners to do invasive procedures in the intensive care unit. Chest. 2008;134:58S.

13. Sapre N, Bugeja P, Hayes E, Corcoran NM, Costello A, Anderson PD. Nurse-led flexible cystoscopy in Australia: initial experience and early results. BJU Int. 2012;110 Suppl 4:46-50. https://doi.org/10.1111/j.1464-410X.2012.11472.x

14. Williams J, Russell I, Durai D, Cheung WY, Farrin A, Bloor K, et al. Effectiveness of nurse delivered endoscopy: findings from randomised multi-institution nurse endoscopy trial (MINuET). BMJ. 2009;338:b231.

15. Mohamed Ryian, Ramcharan Dhannie, Srikaran Sinduya, Mensch Evelyn. A model of clinical practice: a randomised clinical study evaluating patient satisfaction of nurse-led vs consultant-led intravitreal injection. Eye. 2018;32:1148-9.

16. Gregg E. Nurse-led ranibizumab intravitreal injections in wet agerelated macular degeneration: a literature review. Nurs Stand. 2017;31:44-52. 